Abstracta Iranica Abstracta Iranica

Revue bibliographique pour le domaine irano-aryen

Volume 42-43 | 2021

Comptes rendus des publications de 2019-2020

\title{
Rocco Rante, Djamal Mirzaakhmedov, The Oasis of Bukhara. Volume 1: Population, Depopulation and Settlement Evolution
}

\section{Camille Rhoné-Quer}

\section{(2) OpenEdition \\ Journals}

Édition électronique

URL : https://journals.openedition.org/abstractairanica/53125

DOI : 10.4000/abstractairanica.53125

ISSN : 1961-960X

Éditeur :

CNRS (UMR 7528 Mondes iraniens et indiens), Éditions de l'IFRI

Référence électronique

Camille Rhoné-Quer, «Rocco Rante, Djamal Mirzaakhmedov, The Oasis of Bukhara. Volume 1:

Population, Depopulation and Settlement Evolution », Abstracta Iranica [En ligne], Volume 42-43 | 2021,

document 4, mis en ligne le 30 décembre 2021, consulté le 12 décembre 2022. URL : http://

journals.openedition.org/abstractairanica/53125; DOI : https://doi.org/10.4000/abstractairanica.

53125

Ce document a été généré automatiquement le 12 décembre 2022.

Tous droits réservés 


\title{
Rocco Rante, Djamal Mirzaakhmedov, The Oasis of Bukhara. Volume 1: Population, Depopulation and Settlement Evolution
}

\author{
Camille Rhoné-Quer
}

\section{RÉFÉRENCE}

Rocco Rante, Djamal Mirzaakhmedov, The Oasis of Bukhara. Volume 1: Population, Depopulation and Settlement Evolution. Leiden \& Boston : Brill, 2019, 292 p. ISBN :

978-9-004-39621-0

1 Cet ouvrage est le premier d'une série de trois volumes consacrés aux évolutions naturelles et démographiques de l'oasis de Boukhara de la fin du $1^{\mathrm{er}}$ millénaire avant $\mathrm{n}$. è. jusqu'à la période timouride $\left(\mathrm{XV}^{\mathrm{e}} \mathrm{s}\right.$.). Y sont publiés les résultats des travaux archéologiques menés depuis 2009, dans le cadre de la MAFOUB (Mission Archéologique Franco-Ouzbèke de l'oasis de Boukhara), soutenue par le Musée du Louvre, dans la continuité des recherches effectuées par l'Institut archéologique de Samarcande et l'Académie des Sciences de Tachkent dans les années 1990. Se fondant sur une approche et une équipe pluridisciplinaires (p. 1b-4b), le projet a permis de rassembler des informations historiques et culturelles sur le lien entre ressources hydriques, événements géoclimatiques et implantations humaines. Ce premier volume se focalise sur les données géomorphologiques et stratigraphiques, en variant les échelles spatiales d'analyse (delta du Zérafshan, oasis et site de Boukhara, autres sites qualifiés parfois de tepe).

2 L'ouvrage compte 9 chapitres, organisés en deux parties, une conclusion - et sa traduction en russe -, ainsi que 216 figures (cartes, photos, images satellites, plans topographiques, etc.), une bibliographie et un index. 
3 La $1^{\text {ère }}$ partie rassemble le matériau d'une "enquête " (The survey) sur les réseaux hydriques et urbains, replacés dans le contexte régional. Y sont incluses des données topographiques et une typologie des villes, bipartites et tripartites. La $2^{\text {ème }}$ partie (The excavation (sic)) offre une mise en relation des diverses informations sur les six sites identifiés (Boukhara, Paykend, Iskijkat, Kakishtuvan, Ramitan et le «site 250 » étroitement lié à cette dernière localité) et des données archéologiques issues des fouilles menées pendant ce programme de recherche. Autant de données permettant d'appréhender les processus d'évolution urbaine dans la longue durée: sont ainsi identifiées diverses phases d'essor des activités économiques, de dépeuplement, de déplacement des habitants vers le shahristan ou les faubourgs, ou encore, à l'époque islamique, d'abandon des citadelles en contexte urbain - et non sur les sites ruraux. Ces diverses phases, dont la datation remet partiellement en cause les repères chronologiques généralement reconnus, sont l'objet d'une synthèse dans la conclusion (p. 261-267).

\section{AUTEURS}

\section{CAMILLE RHONÉ-QUER}

Université d'Aix-Marseille 